EESTI NSV TEADUSTE AKADEEMIA TOIMETISED. XIII KÖIDE FCUSIKA-MATEMAATIKA- JA TEHINIKATEADUSTE SEERIA. 1964, NR. 4

ИЗВЕСТИЯ АКАДЕМИИ НАУК ЭСТОНСКОП ССР. ТОМ ХІІ СЕРИЯ ФИЗНКО-МАТЕМАТИЧЕСКИХ И ТЕХНИЧЕСКИХ НАУК. 1964, № 4

\title{
СООСАЖДЕНИЕ НИКЕЛЯ И КОБАЛЬТА СУЛЬФИДОМ КАДМИЯ В ПРИСУТСТВИИ ДИЭТИЛДИТИОКАРБАМАТА НАТРИЯ
}

\author{
А. МИЛЛЕР, \\ кандидат химических наук
}

Э. ИОХАННЕС

Сульфид кадмия является хорошим коллектором для концентрирования микропримесей многих элементов. На основе этого свойства CdS в поисках рудных месторождений разработан и внедрен широко в практику метод химико-спектрального анализа - способ ВИТР-ЛТИ, позволяющий концентрировать и полуколичественно определять микропримеси $\mathrm{Cu}, \mathrm{Zn}, \mathrm{Pb}, \mathrm{Hg}, \mathrm{V}, \mathrm{W}, \mathrm{Mo}, \mathrm{Mn}, \mathrm{Sn}, \mathrm{Ag}, \mathrm{Ga}, \mathrm{Ge}$ и др. в природных водах $[1,2,3]$.

При рН G-7 сульфид кадмия в присутствии малого количества хлорного железа соосаждает большинство указанных элементов до 80-100\%. Однако не все элементы, образующие труднорастворимые сульфиды или гидроокиси, могут быть концентрированы одним коллектором при определенных условиях с достаточной полнотой. В этом и заключается трудность группового концентрирования микропримесей. Из интересующих нас элементов это относится, прежде всего, к никелю и кобальту, плохо соосаждаемым с CdS при рН $6-7$ (Со около 60\%. $\left.\mathrm{Ni} 10-30 \%\left[{ }^{1}\right]\right)$, и еще хуже соосаждаемым в кислой среде.

Повышение степени соосаждения $\mathrm{Ni}$ и Со с целыю концентрирования их вместе с другими указанными элементами представляет интерес не только для анализа природных вод, но и для анализа горных пород, в частности эстонских горючих сланцев. Метод группового концентрирования микропримесей соосаждением с $\mathrm{CdS}$ в принципе применим и для последних. Однако относительно высокое содержание железа в горючих сланцах ( $5 \% \mathrm{Fe}_{2} \mathrm{O}_{3}$ в золе) заставляет работать при рН около 3 во избежание осаждения $\mathrm{FeS}$, т. е. в условиях, очень неблагоприятных для соосаждения $\mathrm{Ni}$ и $\mathrm{Co}$.

Нами было изучено влияние ДДТК-Na* на соосаждение $\mathrm{Ni}$ и Co c CdS. Этот реактив ценен тем, что образует труднорастворимые в воде карбаматы никеля и кобальта при рН от 1,5 до $8-9\left[{ }^{4}\right]$, в то время как другие широко применяемые органические реактивы на $\mathrm{Ni}$ и Со (диметилглиоксим, $\alpha$-нитрозо- $\beta$-нафтол, рубеановодородная кислота и др.) дают осадки только в нейтральной или щелочной среде. Хотя применению ДДТК-Na в качестве реактива для отделения, определения и экстракционного концентрирования элементов посвящено много работ, в литературе имеется мало сведений о его использовании в сочетании с неорганическими коллекторами для более полного выделения микропримесей. В. Т. Чуйко и А. У. Маменко [5] концентрировали следы

\footnotetext{
* Диэтилдитиокарбамат натрия.
}

11 ENSV TA Toimetised T-4 64. 
меди из растворов солей кадмия и свинца с применением ДДТК-Na. Г. А. Певцов и Т. Г. Манова $\left.{ }^{6}\right]$ соосаждали $\mathrm{Bi}, \mathrm{Sn}, \mathrm{Cd}$ и $\mathrm{Pb}$ из растворов $\mathrm{NaCl}$ и $\mathrm{KCl}$ сульфидом меди в присутствии ДДТК-Na. Последний применялся для достижения полноты соосаждения микропримесей. Насколько улучшалось соосажденке от прибавления ДДТК-Na, в статье не указано.

Известно, что железо обладает способностью давать труднорастворимый карбамат при $\mathrm{pH}$ ниже 5 . В то же время содержание железа в природных водах и горючих сланцах весьма различно. В силу этого опыты ставились для двух случаев:

1) железа в исследуемом растворе мало (природные воды) и оно вводится дополнительно, как предложено в предыдущих работах $\left[{ }^{2,3}\right]$;

2) в растворе присутствуют значигельные количества железа (кислотные вытяжки из золы горючих еланцев).

Условием применения ДДТК-Na является предотвращение осажления железа в количестве, осложняющем спектральный анализ концентрата. В первом случае это достигается введением определенного количества хлорного железа, а во втором - определенного количества ДДТК-Na и регулированием рН раствора.

Первы й случай. Опыты проводились с эталонными растворами никеля и кобальта, введенными в определенных количествах в 500 мл дважды дистиллированной воды с соблюдением условий методики ВИТР-ЛТИ. Порядок введения реактивов* в раствор следующий:

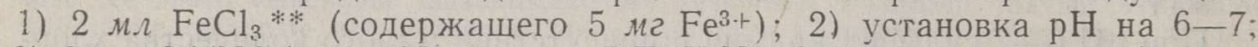
3) $2 m \Omega \mathrm{Cd}\left(\mathrm{NO}_{3}\right)_{2}, 0,4 \mathrm{~N}$; 4) $2 \mathrm{~m}$ ДДТК-Na, 2\%-ного раствора; 5) $3 \mu \Omega$ $\left.\mathrm{Cd}\left(\mathrm{NO}_{3}\right)_{2} ; 6\right) 10$ м $\left.\mathrm{Na}_{2} \mathrm{~S}, 0,4 \mathrm{~N} ; 7\right) 6 \mu \mathrm{Cd}\left(\mathrm{NO}_{3}\right)_{2}$. После прибавления каждого реактива раствор тщательно перемешивали. При введении последней порции $\mathrm{Cd}\left(\mathrm{NO}_{3}\right)_{2}$ в растворе создался некоторый избыток $\mathrm{Cd}^{2+}$, вызвавший быструю коагуляцию осадка. Вес концентрата -300 ме.

Осадки сульфида кадмия обрабатывали 20 мл царской. водки пгри одновременном нагревании, выпаривали до влажных солей, прибавляли 5 мл концентрированной $\mathrm{HCl}$ и снова выпаривали. Соли растворяли в 10-15 мл воды, Содержание $\mathrm{Ni}$ и Со определяли колориметрически [7]. $\mathrm{Ni}$ - диметилглиоксимом с предварительной экстракцией хлороформом; Со - нитрозо-Р-солью.

Эталоны приготовляли осаждением сульфида кадмия по данной мегодике, но без никеля или кобальта. Последние прибавляли к осадку геред обработкой царской водкой, чем достигалось сходство оттенков окраски эталонов й проб.

Для выяснения оптимальных условлй концентрирования в присутствии ДДТК- $\mathrm{Na}$ изучалась зависимость соосаждения от количества колжектора и $\mathrm{pH}$ раствора ігри разных содержаниях никеля и кобальта. ІІри этом соответственно с изменением количества коллектора изменились кроме $\mathrm{FeCl}_{3}$ и ДДТК-Na и количества реактивов.

Результаты для никеля приведены в табл. 1.

Соосаждение никеля при $\mathrm{pH}$ 6-7 с коллектором в количестве 60 ма сильно понижено. Это объясняется образованием карбамата или гидроокиси железа в зависимости от кислотности раствора. При рН ниже 5 железо осаждается в виде карбамата, а последний является

* Очистка реактивов см. в [ $\left.{ }^{3}\right]$.

** $\mathrm{FeCl}_{3}$ очищен путем экстракции эфиром из солянокислого раствора с последующей реэкстракцией водой. 
Таблица 1

\begin{tabular}{|c|c|c|c|}
\hline \multirow{3}{*}{$\begin{array}{c}\text { Содержание } \mathrm{Ni} \\
\text { в растворе } \\
\text { мка }\end{array}$} & \multicolumn{3}{|c|}{ Соосаждено $\mathrm{Ni}, \%$} \\
\hline & \multicolumn{3}{|c|}{ Количество коллектора CdS, мг } \\
\hline & $\begin{array}{c}300 \text { и } 150 \\
\mathrm{pH} 6-7\end{array}$ & $\begin{array}{c}60 \\
\mathrm{pH} 6-7\end{array}$ & $\begin{array}{c}60 \\
\mathrm{pH} 4\end{array}$ \\
\hline $\begin{array}{r}0 \\
5 \\
10 \\
50 \\
100\end{array}$ & $\begin{array}{c}0 \\
80 \\
90 \\
80-100 \\
80-100\end{array}$ & $\begin{array}{r}0 \\
60 \\
60 \\
- \\
-\end{array}$ & $\begin{array}{c}0 \\
80 \\
80-90 \\
80-100 \\
80-100\end{array}$ \\
\hline
\end{tabular}

лучшим коллектором для никеля, чем гидроокись железа или сульфид кадмия в присутствии ДДТK-Na. Для достижения такой же полноты соосаждения при $\mathrm{pH} 6-7$ необходимо работать большими каличествами коллектора $(150-300$ ма).

Отдельной серией опытов было показано, что изменение последовательности введения реактивов в раствор не влияет на результаты анализа.

Поведение коб́альта при указанных условиях опыта не отличается от поведения никеля как по качественным, так и по количественным характеристикам (табл. 2).

Концентраты подвергались

Таблица \&

и спектральному анализу по методике [3]. С применением ДДТК-Na чувствительность определения повысилась почти на целый порядок, составляя теперь $1-3$ мка/л.

В торой случай. Относительно высокое содержание железа в кислотных вытяжках золы горючих сланцев и образование карбамата железа при рН ниже 5 требует точного учета количества ДДТК-Na. Оно должно удовлетворять следующим двум требованиям: осаждать минимальное количество карбамата железа и в то же время обеспечить максимальное соосаждение никеля и кобальта. Кроме того, следует учитывать, что при $\mathrm{pH} \mathrm{3,} \mathrm{наиболее} \mathrm{подходящем} \mathrm{для} \mathrm{концентрирования}$ ряда элементов группы сероводорода и сульфида аммония, раствор ДДТK-Na неустойчив. По данным X. Боде [8], полупериод его разложения при рН 3 равен 3 сек.

Последнее обстоятельство заставило изучать вопрос о целесообразности введения реактива в раствор в виде ДДТК-Na или в виде готового осадка карбамата железа. Также подвергалась изучению зависимость степени соосаждения $\mathrm{Ni}$ и Со от количества ДДТК-Na.

Соосаждение проводилось из 150 мл дважды дистиллированной воды, содержащей определенные количества никеля или кобальта, а также 50 мг железа в виде $\mathrm{FeCl}_{2}$ (свободного от $\mathrm{Ni}$ и $\mathrm{Co}$ ). $\mathrm{FeCl}_{3}$ непригоден ввиду того, что $\mathrm{Fe}^{3}+$ окисляет $\mathrm{H}_{2} \mathrm{~S}$ с обильным выделением $\mathrm{S}$, мешающим проведению опыта. По той же причине в вытяжках из проб горючих сланцев необходимо содержащееся в них $\mathrm{Fe}^{3+}$ восстанавливать до $\mathrm{Fe}^{2+}$.

Последовательность отдельных операций следующая: 1) установка pH 3 ; 2) введение соответствующего количества 1\%-ного раствора 
ДДТК-Na или готового осадка $\mathrm{Fe}(Д Д Т K)_{2}$, приготовленного при $\mathrm{pH} 5$ в 50 мл воды; 3) введение 2 мл $\mathrm{Cd}\left(\mathrm{NO}_{3}\right)_{2}$ (соответствует 60 мг $\left.\mathrm{CdS}\right)$; 4) пропускание быстрого тока $\mathrm{H}_{2} \mathrm{~S}$ (около 150 пузырьков в минуту) через раствор при комнатной температуре в течение 5 мин; 5) отстаивание осадка в течение часа. Содержание никеля и кобальта определялось так же, как и в первом случае.

Результаты по соосаждению 10 мке $\mathrm{Ni}$ с CdS в зависимости от разного количества ДДТК-Na приведены в табл. 3.

таблица з

\begin{tabular}{c|c}
\hline Количество ддтK-Na, & $\begin{array}{c}\text { Соосаждено } \\
\%\end{array}$ \\
\hline 2,5 & $85-90$ \\
1,5 & $80-85$ \\
1,0 & $80-85$ \\
0,5 & $50-55$
\end{tabular}

1,0-1,5 мл $1 \%$-ного раствора ДДТК-Na является оптимальным, так как дальнейшее увеличение количества реактива существенного повышения соосаждаемости не дает. Қоличество $\mathrm{Fe}^{2+}$, осаждаемое с 1 мл ДДТК-Na, равно 1 мг. Оно определялось в концентрате колориметрически по желтому комплексу железа с сульфосалициловой кислотой.

Опыты, поставленные для выяснения целесообразности применения I.ДТK-Na или готового осадка карбамата железа для соосаждения $\mathrm{Ni}$, дали совпадающие результаты. Это показывает, что разложение ДДТК-Na не влияет на результаты, а также позволяет предполагать, что в механизме соосаждения преобладающими являются процессы, иротекающие на поверхности осадка карбамата железа.

Отдельной серией опытов установлено, что степень соосаждения не зависит от того, вводится ли ДДТК-Na в раствор до или после осаждения CdS. Tакже не зависит степень соосаждения от продолжительности отстаивания осадка карбамата железа в течение $2,15,30$ или 60 мин до введения $\mathrm{Cd}\left(\mathrm{NO}_{3}\right)_{2}$ и пропускания $\mathrm{H}_{2} \mathrm{~S}$. Образующийся при этом $\mathrm{CdS}$ является весьма неактивной составной частью коллектора при соосаждении $\mathrm{Ni}$ и Со в кислой среде. Опыты, проведенные с сульфидом кадмия в количестве $150,60,30$ и 15 мг при постоянстве остальных условий, дают одинаковые результаты.

Серией опытов по соосаждению $\mathrm{Ni}$ при оптимальных условиях (60 ма CdS, 1,5 мл ДДТK-Na, отделение осадка через 1 час*) установлено, что в пределах содержания никеля от 5 до 100 мкг в 150 мл раствора степень соосаждения существенно не изменяется. Это иллюстрируется данными табл. 4.

Поведение́ кобальта при вышеописанных условиях опыта не отличается от поведения никеля. Результаты по соосаждению Со при оптимальных условиях, установленных для $\mathrm{Ni}$, совпадают с результатами в табл. 2.

Концентраты, полученные при оптимальных условиях соосаждения, подвергались спектральному анализу по методу ослабления интенсивности линий на три порядка [9]. Условия анализа: спектрограф ИСП-22; дуга переменного тока, величина тока - $15 a$; экспозиция $-2,5$ мин;

* В случае концентрирования только $\mathrm{Ni}$ и Со осадок можно отделить уже через 5-10 мин. Но отделение осадка через час необходимо для того, чтобы провести соосаждение $\mathrm{Ni}$ и Со в условиях, соответствующих наиболее ітолному выделению микрогримесей большой группы элементов совместно с CdS. 
Таблица 4

\begin{tabular}{r|c}
\hline Содержание Ni & Соосаждено $\mathrm{Ni}, \%$ \\
в растворе, мкг & \\
\hline 0 & 0 \\
5 & $80-90$ \\
10 & $80-90$ \\
50 & $80-85$ \\
100 & $80-85$
\end{tabular}

предварительный прогрев пробы в кратере электрода - 10 сек при $2 a$; кратер электрода на 20 мг-2,5×6 6 м, тонкостенный, пропитанный для стабилизации горения дуги раствором лимоннокислого лития; щель - 0,01 мм; освещение щели через трехлинзовый конденсор; пластинки диапозитивные, чувствительность - 0,7 ед. по ГОСТу; проявитель - стандартный. На сжигание бралась $1 / 3$ концентрата, т. е. 20 мг. Чувствительность (мкг элемента в электроде) для никеля (3050. $8 \AA$ А) 1 мк2, для кобальта $(3453,5 \AA$ А) 0,3 мке. Без применения ДДТК-Na никель и кобальт в концентрате не об́наружены.

\section{Выводы}

1. Выявлена возможность применения ДДТК-Na для повышения степени соосаждения никеля и кобальта с $\mathrm{CdS}$ при $\mathrm{pH} 6-7$ и 3 в присутствии разного количества 2 и 3-валентного железа.

2. Установлено, что при условиях данной методики основным соосадителем $\mathrm{Ni}$ и Со является карбамат железа. Для достижения степени соосаждения до $80 \%$ и выше необходимо осаждать не менее 1 мг железа в виде карбамата.

3. Степень соосаждения не зависит от количества CdS при кислотности раствора ( $\mathrm{H}$ ниже 5), благоприятной для образования карбамата железа. При рН выше 5 следует осаждать увеличенные количества $\mathrm{CdS}(150-300$ мг).

4. Степень соосаждения не зависит ни от порядка прибавления осаждающих реагентов, ни от того, вводится ли в раствор ДДТК$\mathrm{Na}$ или готовый осадок карбамата железа.

5. В результате применения ДДТК-Na имеется возможность концентрировать $\mathrm{Ni}$ и $\mathrm{Co}$ с $\mathrm{CdS}$ вместе с лругими элементами группы сероводорода и сульфида аммония с достаточной полнотой как в нейтраль. ной, так и в кислой среде.

\section{ЛИТЕРАТ У РА}

1. Д егтяренко А. П., Либина Р. И., Миллер А. Д., Гидрохимические материалы, т. 29. Изд. АН СССР, 1959.

2. Миллер А. Д., С те п анов А. П., ВИТР, Обмен опытом, вып. 17, 1959.

3. Методическое руководство по определению микрокомпонентов в природных водах при поисках рудных месторождений. Госгеолтехиздат, М., 1961, стр. 225.

4. Че р нихов Ю. А., Добкин а Б. М., Зав. лаб., 15, № 10, 1143 (1949).

5. Ч уй ко В. Т., М а ме нко А. У., Ж. анал. хим., 11, № 3,332 (1956).

6. Певцо в Г. А., М а нов а Т. Г., Ж. анал. хим., 16, № 6, 720 (1961).

7. Сендэл Е. Б., Колориметрическое определение слсдов металлов, Госхимиздат, M., 1949, стр. 271, 354.

8. Bode H., Z. anal. Chem., 142, H. 6, 414 (1954). 
9. Клер М. М. и др., Приближенный количественный спектральный анализ минерального сырья, основанғый на ослаблении интенсивности спектральных линий на три порядка, Госгеолтехиздат, М., 1959.

Институт геологии

Академии наук Эстонской ССР
Поступила в редакцию

25 XI 1963

\title{
NIKLI JA KOOBALTI KAASASADESTAMINE KAADMIUMSULFIIDIGA NAATRIUM-DIETUULDITIOKARBAMAADI JUURESOLEKUL
}

A. Miller, E. Johannes

\section{Resümee}

Paljude elementide :mikrohulkade grupiviisilisel rikastamisel kaadmiumsulfiidiga on $\mathrm{Ni}$ ja Co rikastusaste neutraalses ja happelises keskkonnas väike. Na-dietüülditiokarbamaadi kasutamisega on võimalik $\mathrm{Ni}$ ja Co kaasasadestumist suurendada $80-100 \%$-ni. Artiklis esitatud metoodika on rakendatav $\mathrm{Ni}$ ja $\mathrm{Co}$ mikrohulkade keemilis-spektraalseks määramiseks looduslikes vetes ja pōlevkivis.

Eesti NSV Teaduste Akadeemia

Geoloogia Instituut
Saabus toimetusse

25. XI 1963

\section{COSEPARATION OF NICKEL AND COBALT WITH GADMHUM SULPHIDE IN THE PRESENCE OF SODIUM DIETHYLDITHIOCARBAMATE}

\author{
A. Miller, E. Johannes
}

\section{Summary}

At an enrichment, groupwise, of microamounts of many elements with cadmium sulphide, the degree of enrichment of $\mathrm{Ni}$ and $\mathrm{Co}$ in neutral and acid media is but inconsiderable. With an application of sodium diethyldithiocarbamate it is possible to increase the coseparation of $\mathrm{Ni}$ and $\mathrm{Co}$ as much as $80-100 \%$. The method proposed in the article is applicable for a chemical-spectral determination of microamounts of $\mathrm{Ni}$ and $\mathrm{C}_{0}$ in natural waters and oil shale.

\footnotetext{
Academy of Sciences of the Estonian S.S.R., Institute of Geology
}

Received

Nov. 25th, 1963 